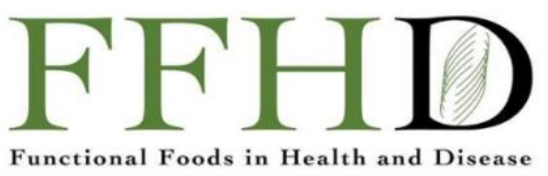

\title{
Spirulina, wakame or goji berries do not lower markers of low- grade systemic inflammation in healthy subjects
}

\author{
José J. van den Driessche, Ronald P. Mensink, Jogchum Plat*
}

Department of Nutrition and Movement Sciences, NUTRIM School for Nutrition and Translational Research in Metabolism, Maastricht University Medical Center+, Maastricht, the Netherlands.

*Corresponding Author: Jogchum Plat, Professor, Department of Nutrition and Movement Sciences, NUTRIM School for Nutrition and Translational Research in Metabolism, Maastricht University Medical Center+, Maastricht, the Netherlands.

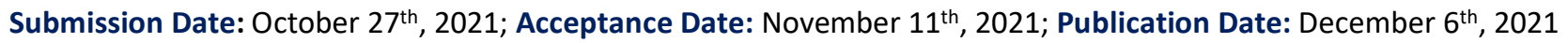

Please cite this article as: van den Driessche J.J., Mensink R.P., Plat J. Spirulina, wakame or goji berries do not lower markers of low-grade systemic inflammation in healthy subjects. Functional Foods in Health and Disease 2021; 11(12): 627-640. DOI:

\section{https://www.doi.org/10.31989/ffhd.v11i12.853}

\section{ABSTRACT}

Introduction: We have earlier reported that consumption of the algae spirulina (Arthrospira platensis or maxima) and wakame (Undaria pinnatifida) for 17 days, and a single dose of goji berries (Lycium barbarum) did not affect fasting or postprandial CVD risk markers in healthy subjects. However, evidence is increasing that low-grade systemic inflammation is also an important marker for CVD risk. Based on information from in vitro and animal studies, we hypothesize that both consumption of the algae spirulina and wakame as well as a single dose of goji berries lowers markers for low-grade inflammation.

Methods: Two randomized, placebo-controlled, crossover trials were performed. In the algae study, 35 nonhypercholesterolemic, healthy subjects consumed 4.8 grams of spirulina, wakame or placebo for 17 days, separated by 14-day washout periods. After 17 days, fasting serum TNF $\alpha$, IL-6, IL-8, and hsCRP concentrations were measured. In the goji berry study, 17 healthy, overweight men received a mixed meal with or without 25 grams of dried goji berries. Before and up to 4 hours after meal intake, serum concentrations of TNF $\alpha$, IL- 6 and IL-8 were measured.

Results: Consumption of spirulina or wakame did not affect serum concentrations of TNF $\alpha$, IL-6, IL-8 or hsCRP. In the goji berry study, serum IL-6 and IL-8 concentrations increased postprandially. For IL-8, these increases were more pronounced after the goji berry meal compared to the control meal $(P=0.003)$. No effects on TNFa were observed.

Conclusion: 17 days of spirulina or wakame consumption, or a single dose of goji berries did not lower markers of lowgrade systemic inflammation in healthy, non-immunocompromised subjects. It is plausible that anti-inflammatory effects of these interventions can only be expected in subjects with an inflammatory risk.

Keywords: spirulina, wakame, goji berries, low-grade systemic inflammation, cytokines, human intervention study 


\section{Two randomized, placebo-controlled, crossover trials}

\section{$\mathrm{N}=35$ non-hypercholesterolemic, healthy subjects}

\section{8 grams spirulina, wakame or placebo}

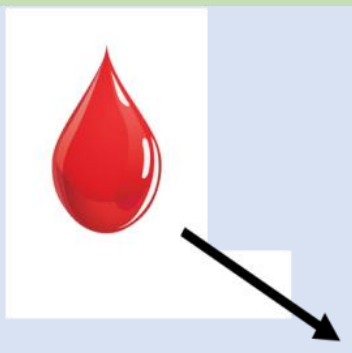

\section{7 healthy, overweight men}

\section{5 grams dried goji berries}

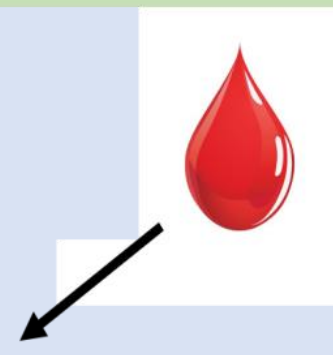

\section{Inflammatory markers}

CFFC 2021. This is an Open Access article distributed under the terms of the Creative Commons Attribution 4.0 License (http://creativecommons.org/licenses/by/4.0)

\section{INTRODUCTION}

Dyslipidemia, hyperglycemia, hypertension, and obesity are well-known risk factors for cardiovascular diseases (CVDs) [1-2]. In addition, evidence is accumulating that postprandial hyperlipidemia and hyperglycemia also contribute to an elevated risk [3-4]. Last, markers of lowgrade systemic inflammation such as for example hsCRP, are associated with CVD risk independent of the classical risk factors [5]. In fact, it has been shown that lowering inflammation, more specific interleukin 6, reduced the occurrence of CVD events, even if lipid profiles were not affected [6]. Therefore, it is important to evaluate whether interventions not only affect the classical CVD risk factors, but also those related to low-grade systemic inflammation.

We have recently examined the effects of three different nutritional compounds on classical CVD risk factors. It was found that the consumption of the algae spirulina (Arthrospira platensis or maxima) or wakame
(Undaria pinnatifida) by non-hypercholesterolemic men and women for 17 days did not affect serum lipid or plasma glucose concentrations, and blood pressure [7]. In another study, we examined the acute effects of a single dose of goji berries (Lycium barbarum fruit) on postprandial triacylglycerol and glucose concentrations in healthy, but overweight men [8]. Again, no effects of the intervention on these parameters could be demonstrated. However, several lines of evidence from cell, animal and human studies have suggested that spirulina, wakame, goji berries or their extracts may reduce markers of low-grade systemic inflammation [912], but results were not conclusive [13-16]. Therefore, we hypothesized that both consumption of the algae spirulina and wakame or a single dose of goji berries may lower markers for low-grade inflammation. To accept or refute this hypothesis, two randomized, placebocontrolled, crossover trials to examine the effect of the algae spirulina and wakame, or goji berries on markers of 
low-grade systemic inflammation in well-controlled human intervention trials were performed. In these two studies we analysed changes in serum TNF $\alpha, I L-6, I L-8$, and hsCRP concentrations, either fasting or postprandial.

\section{METHODS AND MATERIALS}

2.1 Study population: Detailed characteristics of the study populations have been published previously [7-8]. Briefly, 36 healthy, non-hypercholesterolemic men and women participated in the algae study. Main inclusion criteria were: BMI between 18 and $30 \mathrm{~kg} / \mathrm{m}^{2}$, stable body weight ( $\leq 3 \mathrm{~kg}$ weight loss or gain in the past 3 months), no use of medication or food supplements known to affect lipid or glucose metabolism or blood pressure, and no elevated fasting serum total cholesterol $1<8.0$ $\mathrm{mmol} / \mathrm{L})$, serum triacylglycerol $(<4.5 \mathrm{mmol} / \mathrm{L})$ and plasma glucose (< $7.0 \mathrm{mmol} / \mathrm{L})$ concentrations as determined during a screening visit. In the goji berry study, eighteen healthy, overweight (BMI $25-30 \mathrm{~kg} / \mathrm{m}^{2}$ ) men participated. Main inclusion criteria were: stable body weight ( $\leq 3 \mathrm{~kg}$ weight loss or gain in the past 3 months), no use of anticoagulants or medications known to affect lipid or glucose metabolism, serum triacylglycerol concentrations below $2.2 \mathrm{mmol} / \mathrm{L}$ and no elevated fasting serum total cholesterol $(<8.0 \mathrm{mmol} / \mathrm{L})$ or plasma glucose (< $7.0 \mathrm{mmol} / \mathrm{L})$ concentrations as determined during a screening visit. All subjects signed informed consent before the screening visit. Both studies were approved by the medical ethical committee of Maastricht University Medical Centre+ (MUMC+) METC 17-30-22 (algae study) and METC 15-30-60 (goji berry study) and registered at clinicaltrials.gov as NCT03380611 (algae study) and NCT02779985 (goji berry study).

2.2 Study design: algae study: The algae study had a randomized, placebo-controlled, double-blind crossover design and consisted of three intervention periods of 17 days each, separated by washout periods of at least 14 days. During each intervention period, subjects consumed in random order spirulina, wakame, or placebo capsules. Twelve capsules, each containing 400 mg spirulina (Flora Health, Burnaby, Canada), 400 mg wakame (Swanson Health, Fargo, North Dakota, USA), or $400 \mathrm{mg}$ microcrystalline cellulose (Radboud UMC, Nijmegen, the Netherlands) had to be consumed daily. Subjects were instructed to take 4 capsules directly after breakfast, lunch, and dinner. Two weeks before the start of and during the study, subjects were asked to refrain from foods and products containing algae. At the end of each intervention period (day 17), subjects visited the university after an overnight fast of at least 12 hours, and fasting blood samples were taken by venipuncture. The day before each visit, subjects were asked to abstain from alcohol consumption and exercise.

2.3 Study design: goji berry study: The goji berry study had a randomized, double-blind, crossover design with two treatments. During two test days, separated by a washout period of at least 7 days, a postprandial test with a mixed meal was carried out. The day preceding each test day, subjects were asked to abstain from alcohol consumption, exercise and coffee consumption (from 12 PM onwards) and to consume a standardized evening meal. After an overnight fast of at least 12 hours, subjects came to university by public transport or by car on the days of the postprandial tests.

Subjects received in a random order a mixed meal containing 25 grams of dried Lycium barbarum fruit (Superfood.nl, The Netherlands) or a control meal. The Lycium barbarum and control meals were matched for energy content (684 kcal and $683 \mathrm{kcal}$ respectively) and macronutrient composition (55 En\% fat, 32 En\% carbohydrate, 12 En\% protein vs. 55 En\% fat, 33 En\% carbohydrate, 12 En\% protein (Table 1). Blood was sampled before (T0) and 30 minutes (T30), 60 minutes (T60), 120 minutes (T120), 180 minutes (T180) and 240 minutes (T240) after meal intake via an intravenous catheter. 
Table 1. Macronutrient composition of the Lycium barbarum and control meal

\begin{tabular}{|c|c|c|}
\hline & Lycium barbarum meal * & Control meal \\
\hline Energy (kcal) & 684 & 683 \\
\hline Total Fat (g) & 41.8 & 41.9 \\
\hline (En\%) & 55 & 55 \\
\hline Carbohydrates (g) & 54.4 & 56.0 \\
\hline (En\%) & 32 & 33 \\
\hline Proteins (g) & 20.3 & 20.3 \\
\hline (En\%) & & 12 \\
\hline
\end{tabular}

Values based on package information. * Lycium barbarum meal contained $25 \mathrm{~g}$ dried Lycium barbarum

\subsection{Blood sampling and analyses: Blood handling} protocols were identical between the algae and goji berry study. Serum separator tubes (Becton, Dickinson and Company, Franklin Lakes, NJ, USA) were used for blood collection. Tubes were allowed to clot for $30-60$ minutes at room temperature and centrifuged at $1300 \times \mathrm{g}$ for 15 minutes at $21{ }^{\circ} \mathrm{C}$. Serum samples were immediately frozen using liquid nitrogen and stored at $-80{ }^{\circ} \mathrm{C}$ until analysis.

Serum concentrations of interleukin 6 (IL-6), interleukin 8 (IL-8) and tumor necrosis factor alpha (TNF $\alpha$ ) were measured using a multi-array detection system based on electro-chemiluminescence technology (MesoScaleDiscovery, SECTOR Imager 2400, Gaithersburg, Maryland, USA) at all indicated visits and time points. Serum high-sensitivity C-reactive protein (hsCRP; immunoturbidimetric assay, Horiba $A B X$, Montpellier, France) concentrations were measured in samples from all indicated visits within the algae study and in baseline (TO) samples within the goji berry study. All samples from a subject were analyzed in the same analytical run.

2.5 Statistics: Sample size calculations were based on the primary outcome parameters, cholesterol-standardized serum campestral concentrations, and energy expenditure for the algae study and goji study respectively [7-8]

Data is presented as mean and standard deviation (SD), unless indicated otherwise. For the algae study, linear mixed models were used to assess differences in end-of-intervention values between the spirulina or wakame with placebo conditions. It was decided a priori that comparisons would only be made between the spirulina and control conditions and between the wakame and control conditions, and not between the spirulina and wakame conditions. Treatment and period were used as fixed factors and subject as random factor. P-values $<0.05$ were considered statistically significant. To test for carry-over effects, the interaction term treatment $*$ period was used. As the interaction terms were not significant, they were omitted from all models. The spirulina and wakame conditions were each compared with the placebo condition using post-hoc tests. To correct for multiple comparisons, P-values < 0.025 were then considered to be statistically significant. Data was analyzed for men and women separately, but no differences in outcomes were found (data not shown).

Within the goji berry study, fasting values between test days were compared using paired-samples T-tests. Changes in postprandial values from baseline were assessed using linear mixed models with diet and time, and the interaction term diet * time as fixed factors, and 
subjects as random factor. Since the interaction term was not statistically significant, it was omitted from all models. Post hoc tests with Bonferroni correction were used to compare time points to baseline if factor time was significant. The incremental area under the curve (iAUC), defined as the area above baseline values, was calculated with the trapezoidal rule [17] for the 4 hours after meal intake and compared using paired-samples Ttests. P-values $<0.05$ were considered statistically significant. Statistical analyses were performed with SPSS 25.0 for Mac (IBM Corp., Armonk, NY, USA).

\section{RESULTS}

3.1 Subjects: One of the 36 subjects that started with the algae study dropped out due to personal reasons during the wakame period of the study. Thus, 35 subjects, 15 men and 20 women, completed the trial. Baseline characteristics of these subjects are shown in Table 2.

Eighteen men participated in the goji berry study, of which one man was removed from the statistical analyses due to a clear absent postprandial response. Baseline characteristics of the 17 men included in the analyses are shown in Table 2. Subjects had a mean age of $59.5 \pm 5.4$ years and a BMI of $27.2 \pm 1.4 \mathrm{~kg} / \mathrm{m}^{2}$.

Table 2. Mean $( \pm S D$ ) baseline characteristics of the 35 men and women and 17 men included in the analyses within the algae and goji berry study respectively.

\begin{tabular}{|l|l|l|}
\hline & Algae study $(\mathbf{n}=35)$ & $17 / 0$ \\
\hline Men / women, $\mathbf{n}$ & $15 / 20$ & $59.5 \pm 5.4$ \\
\hline Age (y) & $40.2 \pm 19.6$ & $27.2 \pm 1.4$ \\
\hline BMI (kg/m $)$ & $24.7 \pm 2.7$ & \\
\hline Weight (kg) & $71.9 \pm 12.1$ & $86.5 \pm 6.5$ \\
\hline Total cholesterol (mmol/L) & $4.9 \pm 1.1$ & $5.3 \pm 0.7$ \\
\hline Triacylglycerol (mmol/L) & $1.1 \pm 0.6$ & $1.2 \pm 0.4$ \\
\hline Glucose (mmol/L) & $5.2 \pm 1.0$ & $5.3 \pm 0.4$ \\
\hline
\end{tabular}

3.2 Algae study: As shown in Table 3, IL-6, IL-8 and TNF $\alpha$ concentrations did not differ between the spirulina and placebo conditions $(P=0.671, P=0.421, P=0.122$ respectively), or between the wakame and placebo conditions $\quad(P=0.148, \quad 0.484,0.633$ respectively). Moreover, also serum hsCRP concentrations (Table 3) did not differ between the spirulina $(P=0.520)$ or wakame ( $P$ $=0.116)$ and placebo conditions. When stratifying for serum hsCRP concentrations below $(n=27)$ or above $(n=$ 8) $2.0 \mathrm{mg} / \mathrm{L} \mathrm{[6]} \mathrm{at} \mathrm{the} \mathrm{end} \mathrm{of} \mathrm{the} \mathrm{placebo} \mathrm{period,} \mathrm{still} \mathrm{no}$ differences were found between the spirulina and wakame conditions versus placebo. 
Table 3. Mean ( \pm SEM) serum concentrations of interleukin 6 (IL-6), interleukin 8 (IL-8), tumor necrosis factor alpha $(T N F \alpha)$, and high-sensitivity C-reactive protein (hSCRP) after spirulina, wakame and placebo intake $(n=35)$

\begin{tabular}{|c|c|c|c|c|c|}
\hline & \multirow[t]{2}{*}{ Spirulina } & \multirow[t]{2}{*}{ Wakame } & \multirow[t]{2}{*}{ Placebo } & \multicolumn{2}{|c|}{ Estimated difference (versus placebo) ${ }^{a}$} \\
\hline & & & & Spirulina & Wakame \\
\hline IL-6 (pg/mL) & $0.62 \pm 0.11$ & $0.81 \pm 0.17$ & $0.59 \pm 0.09$ & $0.03(-0.14-0.21)$ & $0.13(-0.05-0.30)$ \\
\hline IL-8 (pg/mL) & $14.31 \pm 0.83$ & $13.28 \pm 0.85$ & $13.75 \pm 0.89$ & $0.53(-0.78-1.85)$ & $-0.46(-1.781-0.85)$ \\
\hline $\begin{array}{l}\text { TNF } \alpha \\
(\mathrm{pg} / \mathrm{mL})\end{array}$ & $3.55 \pm 0.15$ & $3.41 \pm 0.12$ & $3.40 \pm 0.12$ & $0.19(-0.05-0.42)$ & $0.06(-0.18-0.30)$ \\
\hline $\begin{array}{l}\text { hsCRP } \\
\text { (mg/L) }\end{array}$ & $1.95 \pm 0.34$ & $2.36 \pm 0.52$ & $1.69 \pm 0.27$ & $0.27(-0.57-1.11)$ & $0.67(-0.17-1.51)$ \\
\hline
\end{tabular}

\section{a Estimated difference and $95 \%$ confidence interval $(\mathrm{Cl})$, based on estimated marginal means obtained with linear mixed} models

3.3 Goji berry study: Baseline concentrations of markers of low-grade systemic inflammation did not differ between the two test days (data not shown). Four hours after meal intake, serum IL-6 concentrations were significantly increased $(P<0.001$ for factor time, Figure 1). However, changes over time were not affected by the Lycium barbarum meal $(P=0.437$ for factor diet; $P=$ 0.372 for iAUC, Table 4).
Serum IL-8 concentrations were also significantly increased 2 hours after meal intake and remained elevated after 4 hours $(P=0.025$ for factor time, Figure 2). In addition, a significant increase in IL-8 concentrations was found after the Lycium barbarum meal ( $P=0.003$ for factor diet), although iAUCs did not differ between meals ( $P=0.210$, Table 4$)$.

Table 4. Mean ( \pm SEM) iAUCs over 4 hours for serum concentrations of interleukin 6 (IL-6), interleukin 8 (IL-8) and tumor necrosis factor alpha (TNF $\alpha$ ) after Lycium barbarum and control meal consumption.

\begin{tabular}{|c|c|c|}
\hline & Lycium barbarum meal & Control meal \\
\hline IL-6 (pg/mL per $240 \mathrm{~min})$ & $67.1 \pm 22.3$ & $46.2 \pm 16.2$ \\
\hline IL-8 (pg/mL per $240 \mathrm{~min})$ & $387.9 \pm 156.81$ & $206.6 \pm 44.0$ \\
\hline $\mathrm{TNF} \alpha(\mathrm{pg} / \mathrm{mL}$ per $240 \mathrm{~min})$ & $26.5 \pm 6.2$ & $24.0 \pm 6.0$ \\
\hline
\end{tabular}

Serum TNF $\alpha$ concentrations were not changed after meal intake ( $P=0.271$ for factor time, Figure 3 ) and did not differ between meals $(P=0.870$ for factor diet; $P=0.781$ for iAUC, Table 4). As only one subject had hsCRP concentrations above $2.0 \mathrm{mg} / \mathrm{L}$ [6] throughout the study, analyses were not repeated after stratification for hsCRP concentrations. 


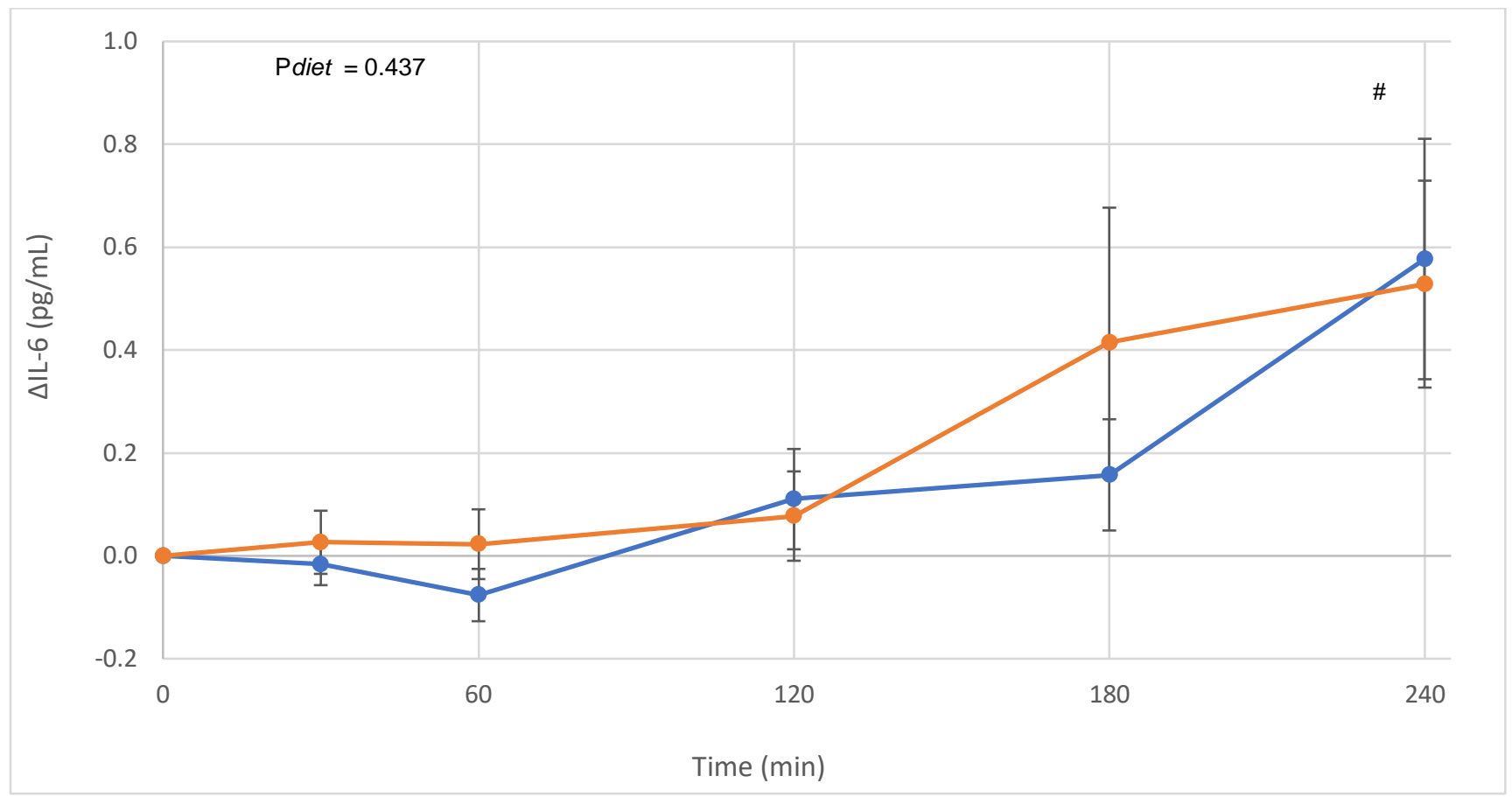

Figure 1. Mean changes $( \pm$ SEM) in interleukin $6($ IL-6) concentrations after Lycium barbarum $(\bullet)$ and control $(\bullet)$ meal consumption $(n=17)$. Data was analyzed using linear mixed models. After Bonferroni correction, factor time was significantly different from baseline values at 240 minutes $(p<0.001)(\#)$.

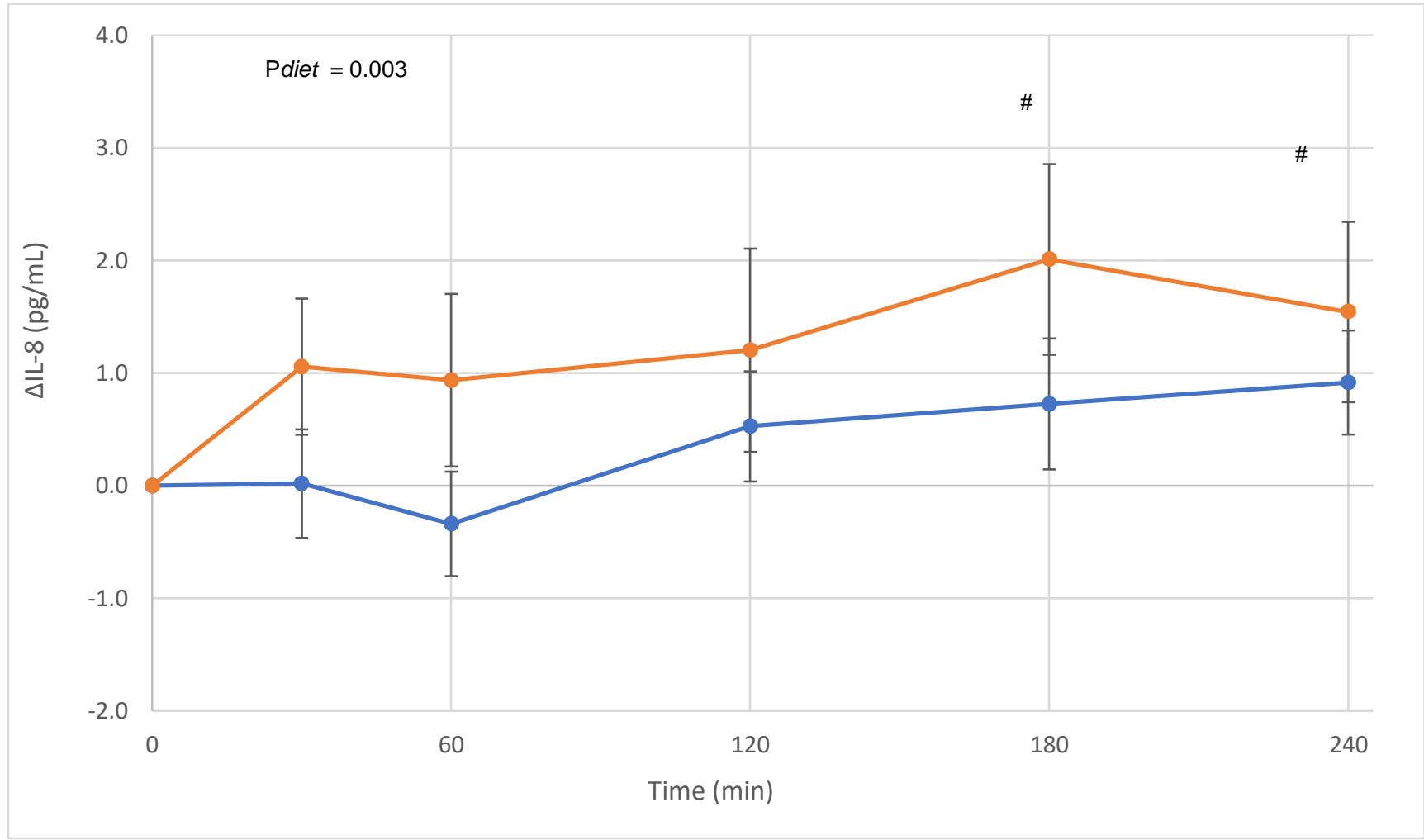

Figure 2. Mean changes $( \pm$ SEM) in interleukin 8 (IL-8) concentrations after Lycium barbarum ( $)$ and control $(\bullet)$ meal consumption ( $\mathrm{n}=17$ ). Data was analyzed using linear mixed models. Significant time effects compared to baseline were found ( $p<0.05$ with Bonferroni correction) (\#). 


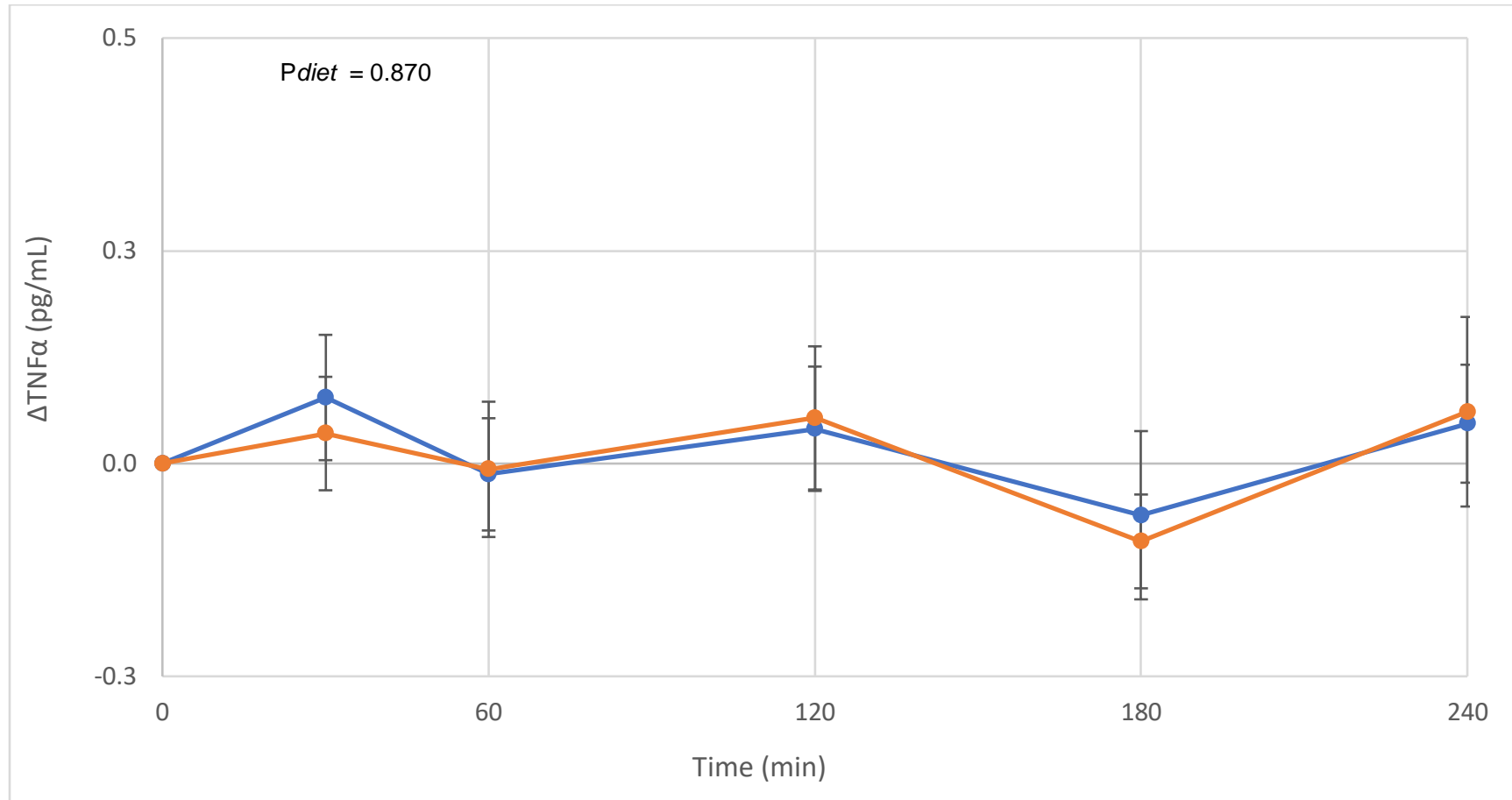

Figure 3. Mean changes $( \pm$ SEM) in tumor necrosis factor alpha (TNF $\alpha$ ) concentrations after the Lycium barbarum meal $(\bullet)$ and control meal $(\bullet)$ in 17 healthy overweight men. Data was analyzed using linear mixed models.

\section{DISCUSSION}

In this study, we found no effects of spirulina or wakame consumption for 17 days on fasting serum IL-6, IL-8, TNF $\alpha$ or hsCRP concentrations, and no effects of a single dose of goji berries on postprandial IL-6 and TNF $\alpha$ concentrations. However, serum IL-8 concentrations increased after intake of a meal with Lycium barbarum as compared to a control meal. Therefore, the hypothesis that consumption of the algae spirulina and wakame as well as a single dose of goji berries lowers markers for low-grade inflammation had to be rejected.

Several in vitro and animal studies have reported anti-inflammatory effects of spirulina consumption. In vitro, pretreatment with a spirulina extract reduced the expression and secretion of TNF $\alpha$, IL-1b and IL- 6 by LPSstimulated RAW 264.7 and murine peritoneal macrophages $[18,19]$. In animals, expression or secretion of pro-inflammatory cytokines, including TNF $\alpha$, IL-1 $\beta$ and
IL-6, was reduced in rats with carrageenan-induced paw oedema [20], splenocytes from high-fat diet-fed mice [21], and kidney tissue from NIC intoxication treated mice [22] after spirulina or spirulina extract treatment. However, human studies on the effects of spirulina on circulating inflammatory markers are scarce and not conclusive. In line with our results, serum TNF $\alpha$ and IL-6 concentrations were not altered after spirulina consumption in type II diabetics [14]. On the other hand, IL-4 concentrations produced by ex vivo PHA-stimulated peripheral blood mononuclear cells (PBMCs) isolated from allergic rhinitis patients were decreased after consuming spirulina for 12 weeks [23]. In addition, spirulina consumption for 3 months decreased IL-6 concentrations compared to placebo in obese hypertensive subjects, whereas TNF $\alpha$ concentrations were not affected [12]. In elderly, IL-2 concentrations increased in men and women and IL-6 concentrations 
decreased in men only after 4 months of spirulina consumption [11]. No effects on TNF $\alpha$ concentrations were found. Interestingly, the increased IL-2 concentrations upon spirulina consumption [11] may have an immune stimulatory effect. Indeed, in PBMCs isolated from men above 50 years consuming a spirulina extract formula, production of IL-2 was increased in response to antigen stimulation, whereas IL-4 concentrations decreased [24]. In addition, concentrated spirulina increased IL-1 $\beta$ and IL-4 production in resting and PHA-stimulated PBMCs [25] and a spirulina extract increased mRNA levels of IL-1 $\beta$ and TNF $\alpha$ in THP-1 macrophages [26]. In other words, both antiinflammatory as well as immune-stimulating effects have been reported in stimulated and non-stimulated conditions, which seems contradictive. However, it should be noted that study designs together with outcome parameters differed largely between the human studies and might have contributed to the apparent discrepancies. Effects of spirulina consumption on cytokine production were measured in ex vivostimulated conditions [24-25] and in vivo non-stimulated $[11-12,14]$. Outcomes of these two different approaches may not correlate and lead to different conclusions [27]. In addition, variation in study population adds to the complexity of comparing studies. Spirulina consumption may affect the types of cytokines produced in subjects with a disturbed Th1/Th2 balance, such as allergic rhinitis patients and elderly [28-29], thereby explaining the reported effects on IL-4 and IL-2. However, it does not explain the inconsistency in effects on IL-6 concentrations. In populations characterized by lowgrade systemic inflammation [30], IL-6 concentrations decreased in elderly and obese hypertensives [11-12], but not in type II diabetics [14]. It is, however, an assumption that these populations were characterized by low-grade systemic inflammation. The studies did not report hsCRP concentrations at baseline and this clinical marker would be of interest to compare status of low-grade inflammation between study populations. In our healthy population, no effects were found as well. Intake cannot be the explaining factor, since 8 grams per day yielded both no [14] as well as IL-6 lowering effects [11] and 2 grams a day also lowered IL-6 concentrations in vivo [12].

For wakame, in vitro studies have reported antiinflammatory effects of the wakame constituents fucoidan and fecosterol. In adipocytes [31] LPSstimulated macrophages [32-33] and microglial cells [34], production of pro-inflammatory cytokines TNF $\alpha$, IL-1 $\beta$ and IL-6 was inhibited. These results were supported by a study in high-fat diet-fed Wistar rats, in which wakame lowered plasma levels of CRP and IL-6 expression in white adipose tissue [9]. In C57BL/6N mice, however, wakame did not affect plasma IL-6 concentrations [35]. Only one human trial has evaluated the effects of wakame consumption on markers of low-grade systemic inflammation. In subjects with the metabolic syndrome, consumption of 4 or 6 grams wakame daily for 1 month did not affect CRP concentrations [15], which is in line with our study. Although in vitro studies were promising, results cannot be translated to humans. A possible explanation for this might relate to dose. Extracts of wakame used in the in vivo experiments were generally less concentrated than those used in in vitro experiments. Also, in vivo metabolism of the extracts may have influenced outcomes. 
Acute effects of goji berry consumption on markers of low-grade systemic inflammation have not been investigated in humans yet. However, a few longer-term intervention studies have suggested potential effects. First, in healthy elderly, consumption of a milk-based goji berry formulation for 3 months did not alter circulating hsCRP and IL-6 concentrations [16]. Second, IL-2 concentrations were increased in Chinese elderly after 30 days of goji berry juice consumption [13]. Again, this increase in IL-2 concentrations can be considered as an immune-stimulatory effect, which has also been suggested by in vitro studies with Lycium barbarum extracts. PBMCs stimulated with Lycium barbarum polysaccharides (LBPs) increased mRNA levels of IL-2 and TNF $\alpha$ [36]. In another in vitro experiment, TNF $\alpha$, IL-2 and IL-4 mRNA expressions, and IL-2 production were increased in LBP-treated mouse splenocytes. However, protein production of TNF $\alpha$ and IL-4 were not affected [37]. In contrast, consumption of goji berry extracts by overweight subjects decreased blood mRNA levels of TNF $\alpha$ and IL-6 [10]. Although the number of studies is limited, it seems that the Th1/Th2 balance might be affected, whereas results on IL-6 concentrations are contradictory. In addition, the variety in goji berry interventions, e.g. formulation versus extracts, makes it difficult to compare studies.

It has been suggested that increases in proinflammatory cytokines after high-fat meal intake relate to elevated CVD risk [38]. A single dose of Lycium barbarum however could not inhibit increases in IL-6 and IL-8 concentrations in the postprandial phase. In contrast, we found an unexpected postprandial increase in IL-8 concentrations compared to control. Since the increase in serum IL-8 concentrations was a single observation and not confirmed by changes in TNF $\alpha$ and IL- 6 concentrations, results are difficult to interpret.

In general, the cytokines measured in the discussed studies vary from T-helper cytokines, including IL-2 (Th1) and IL-4 (Th2), to pro-inflammatory cytokines (TNF $\alpha$, IL6, IL-8) and the downstream marker hsCRP. Although Thelper cytokines may play a role in the pathogenesis of atherosclerosis, their link to CVD risk is not well studied [39]. On the other hand, hsCRP and pro-inflammatory cytokines as markers of low-grade systemic inflammation have been clearly linked to CVD risk. Circulating hsCRP and TNF $\alpha$ concentrations are in fact independent predictors for future vascular events and IL-6 concentrations are correlated with future vascular risk [40]. Although the association between IL-8 and CVD risk is controversial [41], its role in the pathogenesis of atherosclerosis is acknowledged [42]. For now, we should therefore focus on hsCRP and pro-inflammatory cytokines when assessing CVD risk, until the link between T-helper cytokines, IL-8 and CVD risk is better established.

The study population is important when assessing immunomodulatory activity. Age, for example, might affect immune function and circulating pro-inflammatory cytokine concentrations [43] In addition, other populations, such as obese subjects and type II diabetics, are characterized by increased low-grade systemic inflammation [30]. However, none of the trials discussed, including ours, actually selected their study population based on the presence of low-grade systemic inflammation. An anti-inflammatory agent (IL-1 $\beta$ antibody), lowering CRP and IL-6 concentrations also decreased CVD mortality and morbidity in patients with 
previous myocardial infarction and a residual inflammatory risk [6]. Only participants with a residual inflammatory risk, defined as CRP concentrations above $2 \mathrm{mg} / \mathrm{L}$, were included. Another anti-inflammatory agent, low-dose methotrexate, was not able to lower CRP and IL-6 concentrations and CVD risk in patients with previous myocardial infarction and additionally type II diabetes or metabolic syndrome [44]. The study population was not screened for residual inflammatory risk, which resulted in markedly lower median CRP concentrations compared to the other trial. It therefore seems plausible that antiinflammatory effects of interventions can only be expected in subjects with an inflammatory risk.

\section{CONCLUSION}

Seventeen days of spirulina or wakame consumption, or a single dose of Lycium barbarum did not lower markers of low-grade systemic inflammation in healthy, nonimmunocompromised subjects.

\section{REFERENCES}

1. Ho KK, Pinsky JL, Kannel WB, Levy D: The epidemiology of heart failure: the Framingham Study. J Am Coll Cardiol 1993, 22:6a13a. https://doi.org/10.1016/0735-1097(93)90455-a.

2. Kenchaiah S, Evans JC, Levy D, Wilson PWF, Benjamin EJ, Larson MG: Obesity and the risk of heart failure. N Engl J Med 2002, 347:305-313. https://doi.org/10.1056/NEJMoa020245

3. Ceriello A, Genovese S: Atherogenicity of postprandial hyperglycemia and lipotoxicity. Rev Endocr Metab Disord 2016, 17:111-6. https://doi.org/10.1007/s11154-016-9341-8

4. Kolovou GD, Watts GF, Mikhailidis DP, Perez-Martinez P, Mora S, Bilianou H: Postprandial hypertriglyceridaemia revisited in the
Abbreviations: CVD: cardiovascular disease, hsCRP: high sensitivity C-reactive protein, iAUC: incremental area under the curve, IL: interleukin, PBMCs: peripheral blood mononuclear cells, SD: standard deviation, TNFa: tumor necrosis factor alpha

Author contributions: JvdD, RPM, and JP designed the manuscript. JvdD performed the measurements. JvdD wrote the manuscript. RPM and JP critically revised the manuscript and approved the final version. All authors contributed to the article and approved the submitted version.

Acknowledgment: The authors would like to thank Maud Beckers for technical support throughout the study.

Funding: This research did not receive any specific grant from funding agencies in the public, commercial, or notfor-profit sectors

Conflict of Interest: The authors declare no conflicting interests.

era of non-fasting lipid profiles: executive summary of a 2019 Expert Panel Statement. Curr Vasc Pharmacol 2019, 17:538-540. https://doi.org/10.2174/1570161117999190517115432

5. Kaptoge S, Di Angelantonio E, Pennells L, Wood AM, White IR, Gao P: C-reactive protein, fibrinogen, and cardiovascular disease prediction. N Engl J Med 2012, 367:1310-1320. https://doi.org/10.1056/NEJMoa1107477

6. Ridker PM, Everett BM, Thuren T, MacFadyen JG, Chang WH, Ballantyne C: Antiinflammatory therapy with canakinumab for atherosclerotic disease. N Engl J Med 2017, 377:1119-1131. https://doi.org/10.1056/NEJMoa1707914 
7. Van den Driessche JJ, Plat J, Konings M, Mensink RP: Effects of spirulina and wakame consumption on intestinal cholesterol absorption and serum lipid concentrations in non hypercholesterolemic adult men and women. Eur J Nutr 2019, https://doi.org/10.1007/s00394-019-02073-7

8. Van den Driessche JJ, Plat J, Plasqui G, Mensink RP: A single dose of goji berries does not affect postprandial energy expenditure and substrate oxidation in healthy, overweight men. J Nutr Metab 2019, 2019:4057143.

https://doi.org/10.1155/2019/4057143

9. Grasa-Lopez A, Miliar-Garcia A, Quevedo-Corona L, PaniaguaCastro N, Escalona-Cardoso G, Reyes-Maldonado E: Undaria pinnatifida and fucoxanthin ameliorate lipogenesis and markers of both inflammation and cardiovascular dysfunction in an animal model of diet-induced obesity. Mar Drugs 2016, 14:148. https://doi.org/10.3390/md14080148

10. Lee YJ, Ahn Y, Kwon O, Lee MY, Lee CH, Lee S: Dietary wolfberry extract modifies oxidative stress by controlling the expression of inflammatory mRNAs in overweight and hypercholesterolemic subjects: A Randomized, Double-Blind, Placebo-Controlled Trial. J Agric Food Chem 2017, 65:309-316.

\section{https://doi.org/ 10.1021/acs.jafc.6b04701}

11. Park HJ, Lee YJ, Ryu HK, Kim MH, Chung HW, Kim WY: A randomized double-blind, placebo-controlled study to establish the effects of spirulina in elderly Koreans. Ann Nutr Metab 2008, 52:322-328. https://doi.org/10.1159/000151486

12. Szulinska M, Gibas-Dorna M, Miller-Kasprzak E, Suliburska J, Miczke A, Walczak-Galezewska M: Spirulina maxima improves insulin sensitivity, lipid profile, and total antioxidant status in obese patients with well-treated hypertension: a randomized double-blind placebo-controlled study. Riv Eur Sci Med Farmacol $2017,21: 2473-2481$

13. Amagase $H$, Sun B, Nance DM: Immunomodulatory effects of a standardized Lycium barbarum fruit juice in Chinese older healthy human subjects. J Med Food 2009, 12:1159-1165. https://doi.org/: 10.1089/jmf.2008.0300
14. Lee EH, Park JE, Choi YJ, Huh KB, Kim WY: A randomized study to establish the effects of spirulina in type 2 diabetes mellitus patients. Nutr Res Pract 2008, 2:295-300.

https://doi.org/10.4162/nrp.2008.2.4.295

15. Teas J, Baldeon ME, Chiriboga DE, Davis JR, Sarries AJ, Braverman LE: Could dietary seaweed reverse the metabolic syndrome? Asia Pac J Clin Nutr 2009, 18:145-154. https://doi.org/10.1089/rej.2011.1241

16. Vidal K, Bucheli P, Gao Q, Moulin J, Shen LS, Wang J: Immunomodulatory effects of dietary supplementation with a milk-based wolfberry formulation in healthy elderly: a randomized, double-blind, placebo-controlled trial. $\begin{array}{lll}\text { Rejuvenation } & \text { Res 2012;15(1):89-97. }\end{array}$ https://doi.org/10.1089/rej.2011.1241

17. Matthews JN, Altman DG, Campbell MJ, Royston P: Analysis of serial measurements in medical research. Br Med J 1990, 300: 230-235. https://doi.org/10.1136/bmj.300.6719.230

18. Ku CS, Pham TX, Park Y, Kim B, Shin MS, Kang I: Edible blue-green algae reduce the production of pro-inflammatory cytokines by inhibiting NF-kappaB pathway in macrophages and splenocytes. Biochim Biophys Acta 2013, 1830:2981-2988. https://doi.org/10.1016/j.bbagen.2013.01.018

19. Nawrocka D, Kornicka K, Smieszek A, Marycz K: Spirulina platensis improves mitochondrial function impaired by elevated pxidative stress in adipose-derived mesenchymal stromal cells (ASCs) and intestinal epithelial cells (IECs), and enhances insulin sensitivity in equine metabolic syndrome (EMS) horses. Mar Drugs 2017, 15:237. https://doi.org/10.3390/md15080237

20. Abu-Taweel GM, Mohsen GA, Antonisamy P, Arokiyaraj S, Kim HJ, Kim SJ: Spirulina consumption effectively reduces antiinflammatory and pain related infectious diseases. J Infect Publ Health 2019, 12:777-782.

\section{https://doi.org/10.1016/j.jiph.2019.04.014}

21. Pham TX, Lee $Y$, Bae M, Hu S, Kang H, Kim MB: Spirulina supplementation in a mouse model of diet-induced liver fibrosis reduced the pro-inflammatory response of splenocytes. Br J Nutr $2019,121: 748-755$. 


\section{https://doi.org/10.1017/S0007114519000126}

22. Zahran WE, Emam MA: Renoprotective effect of Spirulina platensis extract against nicotine-induced oxidative stressmediated inflammation in rats. Phytomedicine 2018, 49:106110. https://doi.org/10.1016/j.phymed.2018.06.042

23. Mao TK, Van de Water J, Gershwin ME: Effects of a Spirulinabased dietary supplement on cytokine production from allergic rhinitis patients. J Med Food 2005, 8:27-30. https://doi.org/10.1089/jmf.2005.8.27

24. Lobner M, Walsted A, Larsen R, Bendtzen K, Nielsen CH: Enhancement of human adaptive immune responses by administration of a high-molecular-weight polysaccharide extract from the cyanobacterium Arthrospira platensis. J Med Food 2008;11(2):313-322.

https://doi.org/10.1089/jmf.2007.564

25. Mao TK, JVDW, Gershwin ME: Effect of spirulina on the secretion of cytokines from peripheral blood mononuclear cells. J Med Food 2000 3:135-140.https://doi.org/10.1089/jmf.2000.3.135

26. Pugh N, Ross SA, ElSohly HN, ElSohly MA, Pasco DS: Isolation of three high molecular weight polysaccharide preparations with potent immunostimulatory activity from Spirulina platensis, aphanizomenon flos-aquae and Chlorella pyrenoidosa. Planta Med 2001, 67:737-742. https://doi.org/10.1055/s-2001-18358

27. Maerkedahl RB, Frokiaer H, Stenbaek MG, Nielsen CB, Lind MV, Lundtoft C: In Vivo and ex vivo inflammatory markers of common metabolic phenotypes in humans. Metab Syndr Relat Disord 2018, 16:29-39.https://doi.org/10.1089/met.2017.0121

28. Sandmand M, Bruunsgaard H, Kemp K, Andersen-Ranberg K, Pedersen AN, Skinhøj P: Is ageing associated with a shift in the balance between Type 1 and Type 2 cytokines in humans? Clin Exp Immunol 2002, 127:107-114. https://doi.org/10.1046/j.1365-2249.2002.01736.x

29. Scadding G: Cytokine profiles in allergic rhinitis. Curr Allergy Asthma Rep 2014, 14:435.

https://doi.org/10.1007/s11882-014-0435-7
30. Donath MY, Shoelson SE: Type 2 diabetes as an inflammatory disease. Nat Rev Immunol 2011, 11:98-107. https://doi.org/10.1038/nri2925

31. Kim KJ, Lee BY: Fucoidan from the sporophyll of Undaria pinnatifida suppresses adipocyte differentiation by inhibition of inflammation-related cytokines in 3T3-L1 cells. Nutr Res 2012, 32:439-447. https://doi.org/10.1016/j.nutres.2012.04.003

32. Kim KJ, Yoon KY, Lee BY: Low molecular weight fucoidan from the sporophyll of Undaria pinnatifida suppresses inflammation by promoting the inhibition of mitogen-activated protein kinases and oxidative stress in RAW264.7 cells. Fitoterapia 2012, 83:1628-1635. https://doi.org/10.1016/j.fitote.2012.09.014

33. Yoo MS, Shin JS, Choi HE, Cho YW, Bang MH, Baek NI: Fucosterol isolated from Undaria pinnatifida inhibits lipopolysaccharideinduced production of nitric oxide and pro-inflammatory cytokines via the inactivation of nuclear factor-kappaB and p38 mitogen-activated protein kinase in RAW264.7 macrophages. $\begin{array}{lll}\text { Food Chem } & \text { 2012, } & \text { 135:967-975 }\end{array}$ https://doi.org/10.1016/j.foodchem.2012.05.039

34. Park HY, Han MH, Park C, Jin CY, Kim GY, Choi IW: Antiinflammatory effects of fucoidan through inhibition of NFkappaB, MAPK and Akt activation in lipopolysaccharide-induced BV2 microglia cells. Food Chem Toxicol 2011, 49:1745-52.

https://doi.org/10.1016/j.fct.2011.04.020

35. Oh JH, Kim J, Lee Y: Anti-inflammatory and anti-diabetic effects of brown seaweeds in high-fat diet-induced obese mice. Nutr Res Pract 2016, 10:42-48.https://doi.org/10.4162/nrp.2016.10.1.42

36. Gan L, Zhang SH, Liu Q, Xu HB: A polysaccharide-protein complex from Lycium barbarum upregulates cytokine expression in human peripheral blood mononuclear cells. Eur J Pharmacol $2003,471: 217-222$.

https://doi.org/: 10.1016/s0014-2999(03)01827-2

37. Chen Z, Kwong Huat Tan B, Chan SH: Activation of T lymphocytes by polysaccharide-protein complex from Lycium barbarum L. Int Immunopharmacol 2008, 8:1663-1671.

https://doi.org/10.1016/j.intimp.2008.07.019 
38. Burdge GC, Calder PC: Plasma cytokine response during the postprandial period: a potential causal process in vascular $\begin{array}{lllll}\text { disease? } & \mathrm{Br} & \mathrm{J} & \text { Nutr } & \text { 2005, }\end{array}$ https://doi.org/10.1079/bjn20041282

39. Madhumitha H, Mohan V, Deepa M, Babu S, Aravindhan V: Increased Th1 and suppressed Th2 serum cytokine levels in subjects with diabetic coronary artery disease. Cardiovasc Diabetol 2014, 13:1. https://doi.org/10.1186/1475-2840-13-1

40. Ridker PM, Luscher TF: Anti-inflammatory therapies for cardiovascular disease. Eur Heart J 2014, 35:1782-1791. https://doi.org/10.1093/eurheartj/ehu203

41. Velasquez IM, Frumento $P$, Johansson $K$, Berglund $A$, de Faire $U$, Leander K: Association of interleukin 8 with myocardial infarction: results from the Stockholm Heart Epidemiology
Program. Int J Cardiol 2014, 172:173-178. https://doi.org/10.1016/j.ijcard.2013.12.170

42. Apostolakis S, Vogiatzi K, Amanatidou V, Spandidos DA: Interleukin 8 and cardiovascular disease. Cardiovasc Res 2009, 84:353-560. https://doi.org/10.1093/cvr/cvp241

43. Albers R, Antoine JM, Bourdet-Sicard R, Calder PC, Gleeson M, Lesourd B: Markers to measure immunomodulation in human nutrition intervention studies. Br J Nutr 2005, 94:452-481.

https://doi.org/10.1079/bjn20051469

44. Ridker PM, Everett BM, Pradhan A, MacFadyen JG, Solomon DH, Zaharris E: Low-dose methotrexate for the prevention of atherosclerotic events. N Engl J Med 2019, 380:752-762.

https://doi.org/10.1056/NEJMoa1809798 